\title{
Lung cancer or sarcoidosis: A diagnostic dilemma
}

\author{
Poornima Ramadas ${ }^{1 *}$, Prathik Krishnan ${ }^{1}$, Aakriti Pandita1, Manju Paul ${ }^{2}$, Christopher Curtiss ${ }^{3}$ and Ajeet Gajra ${ }^{4}$
}

*Correspondence: poornimaramadas@gmail.com

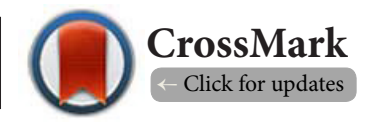

'Department of Internal Medicine, SUNY Upstate Medical University, USA.
2Department of Pulmonary/Critical Care, SUNY Upstate Medical University, USA.
${ }^{3}$ Department of Pathology, SUNY Upstate Medical University, USA.
${ }^{4}$ Department of Hematology and Oncology, SUNY Upstate Medical University, USA.

\begin{abstract}
Background: Small cell lung cancer is a neuroendocrine neoplasm representing about 15 percent of all lung cancers. Sarcoidosis is a multisystem granulomatous disease. The involvement of mediastinal lymph nodes is common in both and makes the diagnosis challenging when these conditions coexist. We report a rare case of a patient with history of sarcoidosis who was diagnosed with small cell lung cancer.

Case presentation: 65-year-old African American female with history of sarcoidosis, who presented with right sided shoulder pain for two months. CT thorax showed right upper lobe nodule with mediastinal and bilateral hilar lymphadenopathy. FDG-PET scan showed increased uptake in the right upper lobe and in mediastinal and hilar lymph nodes. She subsequently underwent an EBUS with biopsies of multiple lymph node stations. Pathology of these lymph nodes revealed non-necrotizing granulomas without evidence of malignancy. She underwent a CT guided biopsy of the right upper lobe lesion and pathology was consistent with small cell carcinoma. It was unclear whether the enlarged and active mediastinal and hilar lymph nodes were related to sarcoidosis or small cell cancer. A multidisciplinary meeting was conducted and decided to treat the patient presumably as small cell cancer with nodal disease. She was given 2 cycles of carboplatin and etoposide. Follow-up CT thorax after the second cycle showed decrease in size of the nodule along with mediastinal and hilar lymph nodes. She also underwent radiation therapy including mediastinum in the field of radiation.

Discussion: Sarcoid-like reactions have been noted either in the vicinity of the tumor or within the regional lymph nodes draining that particular tumor. This has been described in less than 1 percent of lung cancers and mostly in squamous cell lung cancers. True sarcoidosis may be confused with a sarcoid-like reaction in cancer patients. It was not possible to definitively differentiate if the nodal involvement was from sarcoidosis or small cell cancer metastasis or a sarcoid like reaction in our patient. Given the diagnostic dilemma, we treated her nodal involvement as small cell lung cancer metastasis since under treatment could lead to relapse and compromise survival.
\end{abstract}

Keywords: Granuloma, lymph nodes, mediastinum, sarcoidosis, small cell lung carcinoma

\section{Introduction}

Small cell lung cancer is a neuroendocrine neoplasm representing about 15 percent of all lung cancers and is characterized by rapid doubling time and early development of metastasis compared to non-small cell lung cancers. Sarcoidosis is a multisystem granulomatous disease and is characterized by the presence of noncaseating granulomas in involved organs, lung and mediastinal involvement being the most common. The prevalence of sarcoidosis is 10 to 20 per 100,000 population [1]. The involvement of mediastinal lymph nodes is common in both and makes the diagnosis challenging when these conditions coexist. Besides, lung cancers by itself can cause a granulomatous reaction in lymph nodes without metastasis [2], further complicating the clinical picture. We report a rare case of a patient with history of sarcoidosis who was diagnosed with small cell lung cancer, creating a diagnostic dilemma with 
Ramadas et al. Journal of Cancer Therapeutics \& Research 2016,

http://www.hoajonline.com/journals/pdf/2049-7962-5-2.pdf

respects to staging and management.

\section{Case presentation}

65-year-old African American female with history of sarcoidosis, hyperlipidemia and diabetes mellitus, presented to her primary care provider with right sided shoulder and arm pain for the past two months. She had a long standing history of sarcoidosis diagnosed around 17 years ago and was treated with high dose steroids multiple times in the past and is on 2 liters oxygen at night for the past 10 years. She had not been treated with steroids in the recent years and had dyspnea on moderate to severe exertion, which has been stable. She had a 5-pack year history of smoking and quit 20 years ago. $X$-ray of the chest and shoulder were done. X-ray of the shoulder did not reveal any bone lesions. With suspicious abnormality noted on chest X-ray, CT thorax was done which showed right upper lobe apical nodule of $1.1 \mathrm{~cm}$ with mediastinal and bilateral hilar lymphadenopathy. Spirometry showed a FVC of 2.05 I ( $85 \%$ of predicted), FEV1 of 1.4 I (75\% of predicted), FEV1/FVC of $88 \%$, TLC of $83 \%$, but reduced DLCO of $29 \%$. Angiotensin converting enzyme level was normal. FDG-PET scan was done which showed increased uptake in the right upper lobe with 8.3 SUV and in mediastinal and hilar lymph nodes with SUV up to 4.6, possibly secondary to sarcoidosis or metastasis (Figures 1A-1C)and no other areas of increased uptake. She subsequently underwent an EBUS with biopsies of multiple lymph node stations ( $4 \mathrm{~L}, 4 \mathrm{R}, 7,11,11 \mathrm{R})$ and multiple bronchial washings including the right upper lobe. Pathology of all these lymph nodes revealed numerous non-necrotizing granulomas and no evidence of malignancy (Figures 2A and 2B). Bronchial washings showed reactive bronchial cells and normal CD4/CD8 ratio. She went on to have a CT guided biopsy of theright upper lobe lesion. Pathology was consistent with poorly differentiated high-grade neuroendocrine carcinoma, small cell carcinoma (based on cell morphology) in a background of fibrosisand chronic granulomatous inflammation (Figures 3A and 3B). Cells were positive for chromogranin, synaptophysin (Supplementary Figure S1), CK 7, TTF-1 and Ki67 stained $65 \%$ of the cells. Itwas negative

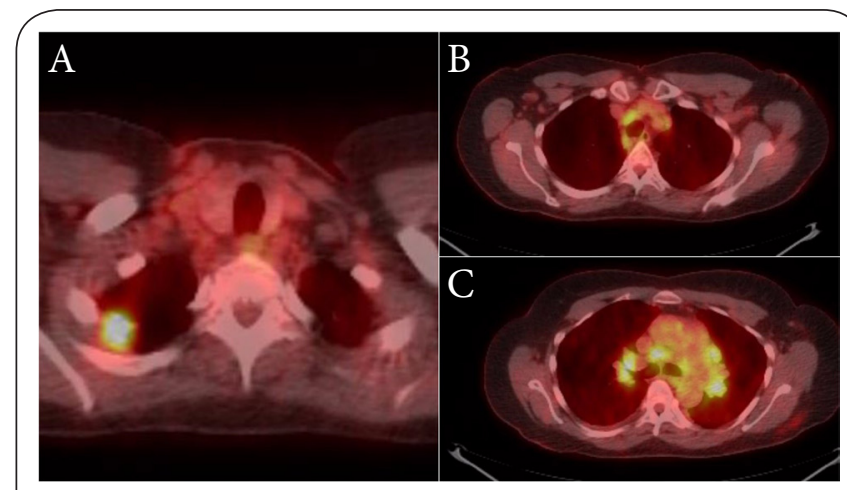

Figure 1. FDG-PET CT: Showing increased uptake in the right upper lobe and in mediastinal and hilar lymph nodes.

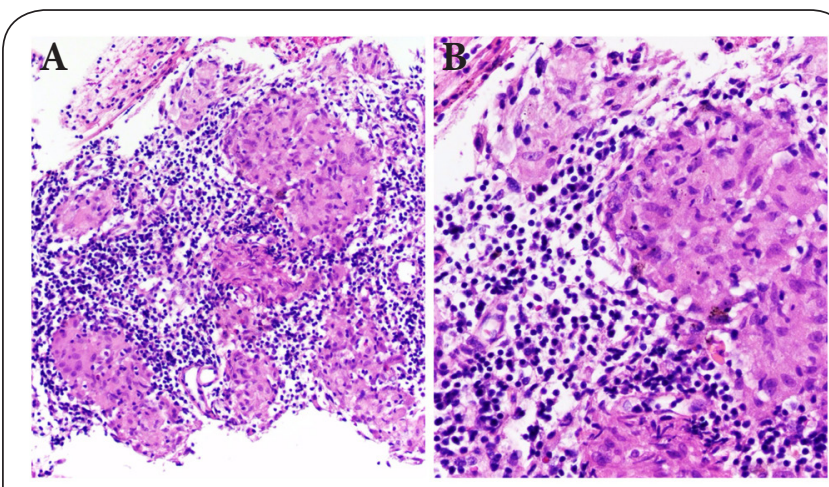

Figure 2. (A) The cellblock material from an EBUS-guided fine needle aspiration (FNA) of a 4 R lymph node reveals multiple small foci of non-necrotizing granulomatous inflammation (100x).

(B) The non-necrotizing granulomas contain wellformed aggregates of epithelioid histiocytes with a tight, circumscribed appearance (200x). Grocott methenamine silver (GMS) stains for fungal organisms and acid-fast bacilli (AFB) stains for mycobacteria were performed to assess for an infectious etiology and were negative. The lack of infectious organisms and the well-circumscribed appearance of the non-necrotizing granulomas is typical of sarcoidosis.

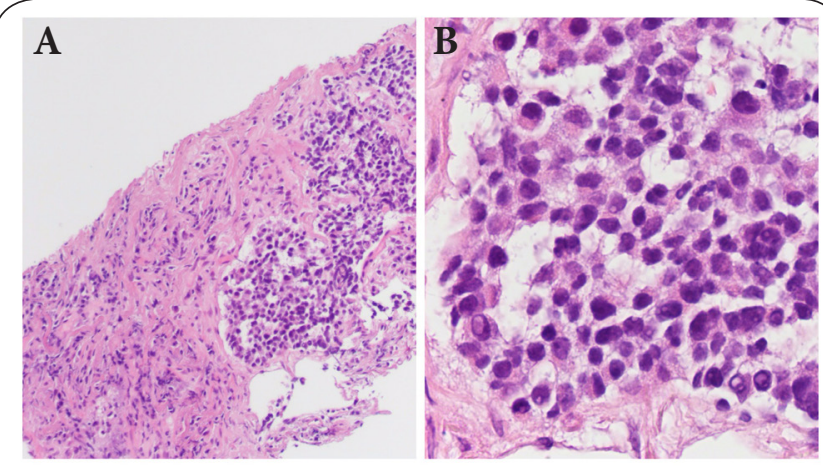

Figure 3. (A) A right upper lobe core biopsy shows nests and infiltrating cords of malignant tumor cells surrounded by fibrous stroma (100x).

(B) The tumor cells contain nuclei with diffuse, fine granular chromatin and occasional small inconspicuous nuclei.

Frequent tumor cell clusters display nuclear molding because the tumor cells have relatively little cytoplasm (400x).

for CK 20, CK 5/6 and CD X2. She was referred to our hospital for further management. It was unclear whether the enlarged and active mediastinal and hilar lymph nodes were related to her sarcoidosis or small cell cancer and her stage was undetermined ( $\mathrm{T} 1 \mathrm{aN} \times \mathrm{M} 0$ ). A multidisciplinary meeting was conducted and decided to proceed with repeat imaging studies and treat the patient presumably as small cell cancer with nodal disease and assess herresponse. She was deemed a poor surgical candidate. Repeat CT thorax (4 months after the initial CT thorax) showed increase in size of the right upper lobe nodule $(1.1$ to $1.6 \mathrm{~cm})$ and right para esophageal 
lymph node ( 1.2 to $1.7 \mathrm{~cm})$, other lymph nodes being stable. She had received no treatment between this and the previous imaging study. MRI brain did not reveal any metastatic disease. She was given 2 cycles of carboplatin and etoposide, 3 weeks apart (Carboplatin on Day 1 and etoposide $80 \mathrm{mg} /$ $\mathrm{m} 2$ on Day 1, 2 and 3). She tolerated the treatment well and follow-up CT thorax after the second cycle showed decrease in size of the nodule $(1.6$ to $1.3 \mathrm{~cm}$ ), mediastinal and hilar lymph nodes. She was evaluated by radiation oncology and underwent concurrent chemo radiation. She received 30 treatments in 15 days ( 4500 cGy) including mediastinum in the field of radiation. She also completed cycle 3 of chemotherapy at the start of radiation and cycle 4 subsequently. She also underwent prophylactic cranial radiation (2500 cGy in 10 fractionations) after completion of chemotherapy. Repeat $\mathrm{CT}$ thorax showed further decrease in size of the lung nodule and lymph nodes and MRI brain was again negative. She is doing well after her treatment course and is under follow up.

\section{Discussion}

Co-existence of sarcoidosis and lung cancer is extremely rare, incidence being less than 1 percent and is usually seen in squamous cell lung cancers. The involvement of mediastinal lymph nodes can be found in both sarcoidosis and lung cancer and this makes the diagnosis challenging. We encountered this interesting experience in the management of our patient.

Sarcoid-like reactions have been described either in the vicinity of the tumor or within the regional lymph nodes draining that particular tumor; and in some cases; such reactions can be seen even in the non-regional lymph nodes [3]. It is observed that these reactions occurred about four times more often in regional lymph nodes without metastasis, than in lymph nodes with metastasis [4]. They are found in 2.4 to 3.4 percent of all lung cancers; more common in patients with squamous cell carcinoma $[3,4]$ and said to be a marker of antitumor response and a good prognosis [5]. There is also evidence that the detection of sarcoid reactions within regional lymph nodes of patients with non-small cell lung carcinoma predicts a lower rate of disease recurrence after surgical resection [5]. Therefore, true sarcoidosis may be confused with local sarcoid-like reaction in cancer patients. In our patient, it was unclear if the EBUS guided lymph node biopsy missed the metastasisor if it was just a sarcoid-like reaction without any metastasis.

There is conflicting data regarding the relationship of sarcoidosis and lung cancer. While some studies suggest that the risk of lung cancer and death from lung cancer is higher in patients with sarcoidosis $[6,7]$, other studies suggest that the incidence may not be higher than expected [8]. However, it is possible that the chronic inflammatory process and scarring along with the abnormalities of cell-mediated immunity secondary to sarcoidosis could be a potential trigger for carcinogenesis. Our patient had a long-standing history of sarcoidosis, which was treated multiple times in the past and could have been a predisposing factor to malignancy.

FDG-PET, a common diagnostic modality to detect increased metabolic activity has $96 \%$ sensitivity and $79 \%$ specificity in lung cancer. A tumor's metabolic activity is measured using the SUV, which when greater than 2.5 is highly suggestive of malignancy. However, in granulomatous conditions like sarcoidosis this test can be false positive [9]. In our patient, the lymph nodes had SUV up to 4.6. Based on this, it was difficult to differentiate whether this was secondary to lung cancer or sarcoidosis, further complicating the clinical picture. Even though elevated Angiotensin converting enzyme levels and elevated CD4/CD8 ratio in broncho alveolar lavage may be seen in patients with sarcoidosis, this was also not seen in our patient. EBUS guided biopsy is the commonly used procedure for lymph node biopsy as it is less invasive and offers excellent results. However, it can be limited with the small size of the sampled specimens, lack of access to the posterior lymph node stations and variable operator efficiency. If EBUS guided biopsy is negative for malignancy, additional biopsy usually with mediastinoscopy might be needed $[10,11]$.

Sarcoidosis is commonly treated with glucocorticoids and second line drugs include immunosuppressants such as methotrexate and azathioprine [12]. There is no data regarding response of chemotherapeutic agents to sarcoidosis. There could have been a response to carboplatin and etoposide that our patient received, even if the lymphadenopathy was secondary to sarcoidosis. Sarcoidosis also responds to radiation therapy and has been used for refractory neurosarcoidosis; and this can be a reason why our patient responded as well [13].

\section{Conclusion}

It was not possible to definitively differentiate if the nodal involvement was from sarcoidosis or small cell cancer metastasis or a sarcoid like reaction in our patient. The decrease in size of the lymphadenopathy from chemotherapy and radiation could be secondary to small cell cancer; it could also be an interval resolution of sarcoidosis. Given this diagnostic dilemma, our multidisciplinary lung cancer team decided to treat her nodal involvement as small cell lung cancer metastasis, since under treatment could lead to relapse and compromise survival.

\section{Additional files}

\section{Supplementary Figure S1}

\section{List of abbreviations}

CT: Computed tomography

DLCO: Diffusing capacity of the lungs for carbon monoxide

FVC: Forced Vital Capacity

FEV: Forced Expiratory Volume

TLC: Total Lung Capacity

FDG-PET: Fludeoxyglucose-Positron emission tomography

SUV: Standardized uptake value

EBUS: Endobronchial ultrasound

$\mathrm{CD}$ : Cluster of differentiation

CK 7: Cytokeratin 7 
Ramadas et al. Journal of Cancer Therapeutics \& Research 2016,

http://www.hoajonline.com/journals/pdf/2049-7962-5-2.pdf

doi: $10.7243 / 2049-7962-5-2$

TTF-1: Thyroid transcription factor-1

CD X2: Caudal Type Homeobox 2

\section{Competing interests}

The authors declare that they have no competing interests.

\section{Authors' contributions}

\begin{tabular}{|l|c|c|c|c|c|c|}
\hline Authors' contributions & PR & PK & AP & MP & CC & AG \\
\hline Research concept and design & $\checkmark$ & -- & -- & $\checkmark$ & -- & $\checkmark$ \\
\hline Collection and/or assembly of data & $\checkmark$ & $\checkmark$ & $\checkmark$ & $\checkmark$ & $\checkmark$ & $\checkmark$ \\
\hline Data analysis and interpretation & $\checkmark$ & $\checkmark$ & -- & -- & $\checkmark$ & $\checkmark$ \\
\hline Writing the article & $\checkmark$ & $\checkmark$ & -- & $\checkmark$ & $\checkmark$ & -- \\
\hline Critical revision of the article & $\checkmark$ & -- & -- & -- & -- & $\checkmark$ \\
\hline Final approval of article & $\checkmark$ & - & -- & $\checkmark$ & -- & $\checkmark$ \\
\hline Statistical analysis & -- & -- & -- & -- & -- & -- \\
\hline
\end{tabular}

\section{Publication history}

Editor: Bechan Sharma, University of Allahabad, India.

EIC: G. J. Peters, VU University Medical Center, Netherlands.

Received: 17-Jan-2016 Final Revised: 03-Mar-2016

Accepted: 14-Mar-2016 Published: 21-Mar-2016

\section{References}

1. Thomas KW and Hunninghake GW. Sarcoidosis. JAMA. 2003; 289:3300-3. | Article | PubMed

2. Kamiyoshihara M, Hirai T, Kawashima O, Ishikawa S and Morishita Y. Sarcoid reactions in primary pulmonary carcinoma: report of seven cases. Oncol Rep. 1998; 5:177-80. | Article | PubMed

3. Brincker H. Sarcoid reactions in malignant tumours. Cancer Treat Rev. 1986; 13:147-56. | Article | PubMed

4. Laurberg P. Sarcoid reactions in pulmonary neoplasms. Scand J Respir Dis. 1975; 56:20-7. I Article | PubMed

5. Steinfort DP, Tsui A, Grieve J, Hibbs ML, Anderson GP and Irving LB. Sarcoidal reactions in regional lymph nodes of patients with early stage non-small cell lung cancer predict improved disease-free survival: a pilot case-control study. Hum Pathol. 2012; 43:333-8. | Article | PubMed

6. Askling J, Grunewald J, Eklund A, Hillerdal G and Ekbom A. Increased risk for cancer following sarcoidosis. Am J Respir Crit Care Med. 1999; 160:1668-72. | Article | PubMed

7. Yamaguchi M, Odaka M, Hosoda $\mathrm{Y}$, Iwai $\mathrm{K}$ and Tachibana T. Excess death of lung cancer among sarcoidosis patients. Sarcoidosis. 1991; 8:51-5. | Article I PubMed

8. Romer FK. Case 7-1982: sarcoidosis and cancer. N Engl J Med. 1982; 306:1490. | Article | PubMed

9. Maeda J, Ohta M, Hirabayashi $\mathrm{H}$ and Matsuda H. False positive accumulation in $18 \mathrm{~F}$ fluorodeoxyglucose positron emission tomography scan due to sarcoid reaction following induction chemotherapy for lung cancer. Jpn J Thorac Cardiovasc Surg. 2005; 53:196-8. | Article | PubMed

10. Defranchi SA, Edell ES, Daniels CE, Prakash UB, Swanson KL, Utz JP, Allen MS, Cassivi SD, Deschamps C, Nichols FC, 3rd, Shen KR and Wigle $D A$. Mediastinoscopy in patients with lung cancer and negative endobronchial ultrasound guided needle aspiration. Ann Thorac Surg. 2010; 90:1753-7. | Article | PubMed

11. Um SW, Kim HK, Jung SH, Han J, Lee KJ, Park HY, Choi YS, Shim YM, Ahn MJ, Park K, Ahn YC, Choi JY, Lee KS, Suh GY, Chung MP, Kwon OJ, Kim $\mathrm{J}$ and $\mathrm{Kim} \mathrm{H}$. Endobronchial ultrasound versus mediastinoscopy for mediastinal nodal staging of non-small-cell lung cancer. J Thorac Oncol. 2015; 10:331-7. I Article | PubMed

12. Baughman RP, Costabel $U$ and du Bois RM. Treatment of sarcoidosis. Clin Chest Med. 2008; 29:533-48. | Article | PubMed

13. Menninger MD, Amdur RJ and Marcus RB, Jr. Role of radiotherapy in the treatment of neurosarcoidosis. Am J Clin Oncol. 2003; 26:e115-8. | Article I PubMed

\section{Citation:}

Ramadas P, Krishnan P, Pandita A, Paul M, Curtiss C and Gajra A. Lung cancer or sarcoidosis: A diagnostic dilemma. J Cancer Ther Res. 2016; 5:2.

http://dx.doi.org/10.7243/2049-7962-5-2 